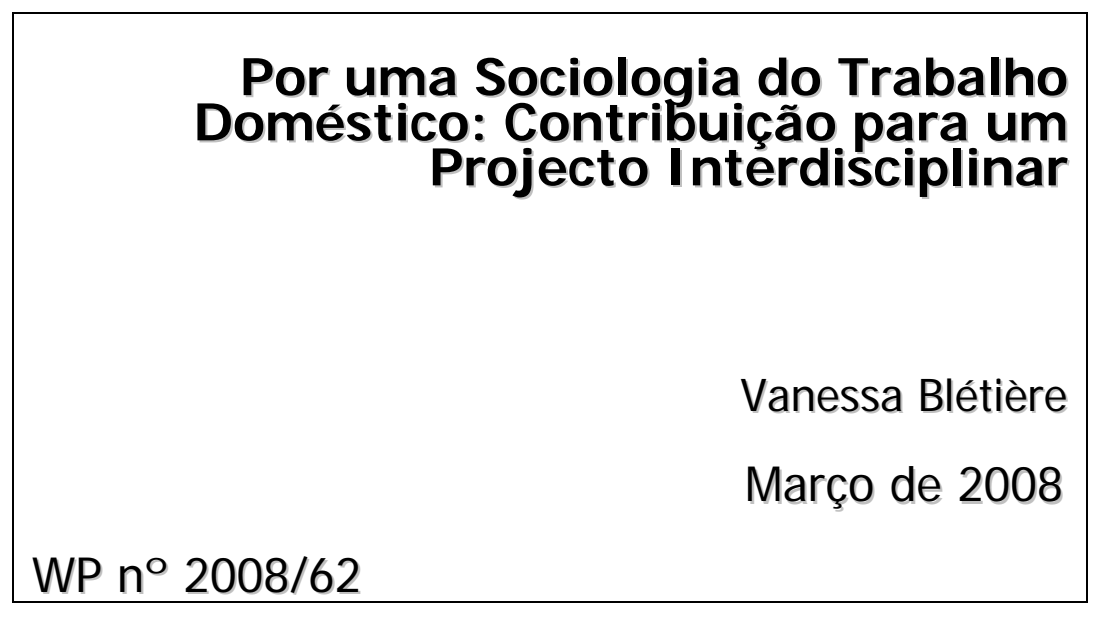

DOCUMENTO DE TRABALHO

WORKI NG PAPER

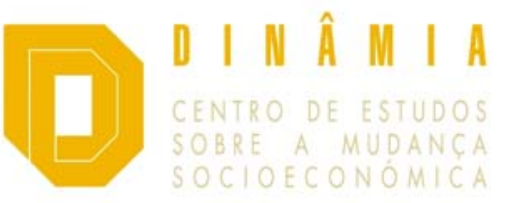


SUMÁRIO

1. INTRODUÇÃO 3

2. O TRABALHO DOMÉSTICO ENQUANTO OBJECTO DE ESTUDO

3. CONTRIBUTOS PARA O ESTUDO DO TRABALHO DOMÉSTICO 8

4. APROXIMAÇÃO TEÓRICA AO CONCEITO DE TRABALHO DOMÉSTICO 10

5. TRABALHADORAS DOMÉSTICAS: PERFIL E TRAJECTÓRIA SOCIAL 19

6. RESPOSTAS ASSOCIATIVAS E GOVERNAMENTAIS 26

7. CONCLUSÃO 31

$\begin{array}{ll}\text { BIBLIOGRAFIA } & 32\end{array}$

${ }^{1}$ Dinâmia / ISCTE. 


\section{Por uma Sociologia do Trabalho Doméstico: Contribuição para um Projecto Interdisciplinar}

\section{SUMÁRIO}

O trabalho doméstico é um fenómeno que se encontra em expansão nos nossos dias, que tem sido objecto de um olhar mais atento por diversos especialistas de variadas áreas de investigação. Sendo este um tema que se expande em diferentes campos de análise, merece uma análise interdisciplinar e comparada que possa garantir o estudo das particularidades que envolvem esta categoria profissional. O presente relatório tem por objectivo discutir as várias características inerentes a esta actividade com o intuito de melhor compreender a sua estrutura. Sendo apenas uma primeira abordagem ao tema Trabalho Doméstico e Trabalhadores Domésticos vai consistir, fundamentalmente, num inventário sumário das contribuições dos principais investigadores que, actualmente, no campo sociológico, se têm debruçado sobre este domínio.

\section{INTRODUÇÃO}

Tendo como principal objectivo traçar as principais linhas de orientação para o estudo do trabalho doméstico e das trabalhadoras domésticas, o presente relatório consiste numa análise transversal das várias dimensões do tema em estudo. Apesar de este ter ainda pouca visibilidade em trabalhos de âmbito científico, verifica-se que o conceito trabalho doméstico acaba por cruzar-se com diversas áreas de investigação, o que reforça a complexidade das discussões que podem surgir em torno deste conceito.

Assim sendo, achou-se pertinente reter aqui algumas ideias que nos apontam para o panorama de como este conceito tem vindo a ser abordado, nas diversas áreas. Será precisamente neste âmbito que iremos desenvolver um primeiro capítulo que será complementado posteriormente com mais informações, após a realização de uma pesquisa mais intensiva sobre o assunto. Sublinhe-se, desde já, um ponto essencial: apesar da quase inexistência de trabalhos de âmbito científico, sobre o tema trabalho doméstico, verifica-se a abundância do uso deste conceito em diversas áreas, sobretudo por parte de especialistas das áreas da sociologia da família e do género. 
Este enquadramento pretende servir de base para o desenvolvimento de um segundo capítulo que terá como principal objectivo identificar os principais autores que se debruçam sobre o tema do trabalho doméstico. Trata-se de encontrar pontos de convergência entre as diversas áreas e trabalhos realizados. Neste segundo capítulo, antes de qualquer aproximação teórica, propor-seá um enquadramento biográfico dos principais especialistas que se têm dedicado ao objecto de estudo em causa, para mostrar quais contextos têm favorecido o desenvolvimento da investigação nesta matéria.

No terceiro capítulo o conceito de trabalho doméstico irá ser discutido, tendo por base as principais teorias que se encontram por detrás de uma construção objectiva desta prática laboral. Neste capítulo pretende-se ir à origem desta actividade, e perceber porque é desempenhada maioritariamente por mulheres, no âmbito de uma abordagem concentrada no domínio da divisão sexual do trabalho. Este capítulo aborda também a definição do trabalho doméstico remunerado, passando por um levantamento das suas características. Pretende-se, ainda, focar as causas de um movimento crescente que se verifica na procura de trabalhadoras domésticas sendo esta o ponto de partida para a discussão dos contornos de um contrato laboral e dos regimes aplicados.

O quarto capítulo centra-se na trabalhadora doméstica, tendo-se aqui especial cuidado em frisar o género feminino, uma vez que os dados estatísticos são explícitos ao traduzirem que são as mulheres que, ainda nos nossos dias, são maioritárias no campo do trabalho doméstico. Por este motivo, tomou-se aqui a liberdade de se falar em trabalhadoras no feminino. Neste sentido, o enfoque aqui será a construção de um perfil da trabalhadora doméstica, recorrendo a dados históricos; a um levantamento de diversas estratégias adoptadas no quadro da relação laboral, com base em alguns resultados de investigações realizadas; por fim, perceber quem se oferece para o trabalho doméstico, quais as dificuldades encontradas; no fundo, dar conta do trabalho doméstico na perspectiva da trabalhadora. Este será o momento em que questões ligadas à imigração serão abordadas.

Por último, pretende-se abordar movimentos que se têm formado ao longo dos anos e que aparecem como respostas à violação dos direitos humanos e à concretização de importantes aç̧ões que influenciam a tomada de decisões legislativas e governamentais enquanto respostas à melhoria das condições de trabalho destas trabalhadoras. 


\section{TRABALHO DOMÉSTICO ENQUANTO OBJECTO DE ESTUDO}

O Trabalho Doméstico, enquanto objecto de estudo, tem permanecido à margem dos principais focos de investigação. Apesar disso, este conceito enquanto prática e representação surge nos mais diversos campos das investigações realizadas no âmbito ciências sociais e, em particular, dos diversos ramos da sociologia.

Em Portugal, encontramos alguns campos de investigação, como é o caso da sociologia da família, onde a referência ao trabalho doméstico é frequente, acompanhando todo um processo de mudança social que parte de uma nova consciência feminina. Esta nova consciência manifesta-se em dados estatísticos onde fica explícita uma mudança de hábitos e estilos de vida das mulheres. Uma mudança que, consequentemente, terá a sua influência em diversos campos da sociedade.

Estes novos hábitos derivam, essencialmente, do processo de passagem da condição de "mulher doméstica” para a condição de se encontrar inserida num campo predominantemente masculino, o mercado de trabalho. Esta alteração, inevitavelmente, vai ter efeitos ao nível da família, dos papéis sociais, da economia, etc.

A sociologia da família aborda, desta forma, diferentes temas onde o trabalho doméstico é frequentemente referido. De forma geral, o trabalho doméstico é focado no âmbito da discussão da divisão de tarefas entre os sexos, dentro do contexto da desigualdade entre os géneros. É precisamente dentro deste quadro que se desenvolvem investigações que cruzam a noção de trabalho doméstico, dado que este traça a linha divisória entre a esfera do privado (domínio maioritariamente feminino, no que se refere às tarefas desempenhadas) e a esfera pública (ou trabalho assalariado, inicialmente dominado pelos homens).

Ao analisarmos investigações realizadas em Portugal, no domínio da família, verificamos que sobretudo no início dos anos 90 existe uma maior concentração de estudos centrados nos novos percursos das mulheres. A mulher aposta cada vez mais na sua formação, embora esteja, ainda, à mercê de um fraco desenvolvimento do mercado de trabalho que não acompanha a evolução dos novos percursos sociais femininos. 
O objecto central da maior parte destes estudos gira em torno destas transformações que se verificam no percurso das mulheres onde o processo de continuidade, e não de ruptura, de tarefas entre o domínio da esfera pública e o domínio da esfera privada parece ser causa de diversos conflitos que surgem entre os dois géneros.

Estes conflitos aparecem, muitas vezes, como objecto de estudo em diversos estudos que centram o seu objecto na divisão de tarefas na família ou nas questões de igualdade de género no trabalho. Sendo este um pano de fundo para estudos que tenham não só como objectivo a análise da divisão sexual destas tarefas, como a comparação que se estabelece entre diversas famílias na perspectiva comparativa das classes sociais.

Em Portugal, vários estudos realizados no campo da sociologia da família e do género ganham especial destaque neste campo. De entre estes, podemos citar aqui os de Anália Torres e Maria das Dores Guerreiro que realizam estudos nesta área e salientam importantes aspectos das transformações ocorridas no percurso social das mulheres.

Os estudos realizados no âmbito do trabalho doméstico, em Portugal, aparentam estar exclusivamente focalizados no trabalho doméstico não remunerado. Um estudo, realizado em 1993 por Ana Nunes de Almeida ${ }^{2}$ incide precisamente neste tema, tendo como principal objectivo analisar os motivos que estão por detrás da escolha de ser ou não esposa doméstica.

O trabalho doméstico remunerado aparece, de igual forma, noutros campos de análise. Não deixa de se situar numa estrutura categorial das classes sociais. É aliás, um factor que pode levar à categorização de uma classe, tendo em conta que esta actividade é rotulada por um baixo status sócio-económico.

O trabalho doméstico remunerado parece, paralelamente, inscrever-se também no campo da sociologia das migrações, uma vez que se verifica um crescente envolvimento de imigrantes no mercado de trabalho doméstico; realidade, esta que parece prevalecer em Portugal. A sociologia do direito terá, evidentemente, um forte contributo na apreensão da realidade social do trabalho doméstico remunerado, uma vez que este se encontra regulamentado por uma lei, sendo de toda a pertinência conhecer a aplicação efectiva da mesma. Tendo em conta todas as particularidades inerentes a este tipo de actividade, é pertinente analisar a prática das leis na esfera privada da família, espaço que fica, tradicionalmente, à margem do âmbito das regulamentações estaduais.

\footnotetext{
2 Almeida, Ana Nunes de, (1993), “Mulheres e Famílias operárias: a esposa doméstica”, in Análise Social, v. 28, $n^{\circ} 120$, Lisboa
} 
Este breve capítulo serviu apenas para traçar linhas de orientação que posteriormente serão desenvolvidas. A noção de que o conceito de trabalho doméstico se estende para diversos campos de análise é imprescindível no quadro de uma investigação centrada apenas na análise desta actividade.

Podemos, desde já, aferir que para prosseguir com esta investigação teremos que tratar o tema de uma forma transversal, partindo dos diversos domínios, com o intuito de se poder afunilar a informação para se chegar a uma construção sociológica do conceito de "trabalho doméstico". 


\section{CONTRIBUTOS PARA O ESTUDO DO TRABALHO DOMÉSTICO}

Apesar da actual escassez de investigações centradas no estudo do Trabalho Doméstico este parece ser um tema em expansão que se constitui enquanto objecto privilegiado para alguns especialistas das áreas das ciências sociais. Procuraremos aqui traçar um mapa das principais linhas de investigação que têm sido realizadas, no plano internacional, ao longo dos anos, nas diversas áreas das ciências sociais.

Convém referir alguns dos principais autores que se debruçam sobre esta área, tendo em conta alguns aspectos biográficos, o que permitirá entender melhor as perspectivas pelas quais o trabalho doméstico tem sido fonte de estudo.

Um dos principais nomes é o de Bridget Anderson; doutorada em Sociologia, esta autora, conta também com uma formação na área da Filosofia e Línguas Modernas. Tem desenvolvido, ao longo dos anos, um extenso trabalho no campo da imigração ilegal, em ligação directa com sindicatos, organizações de imigrantes e outras instituições que actuam em contexto local, nacional e nível europeu.

Os diversos trabalhos de Anderson (Anderson, 2001a, 2001b) centram-se no tema das mulheres imigrantes ilegais, onde o trabalho doméstico parece ganhar um especial relevo enquanto actividade primordial desta população-alvo. Podemos ainda referir que o maior volume de investigações realizadas no âmbito do trabalho doméstico foi realizado entre 1999 e 2002.

Se considerarmos as referências bibliográficas utilizadas pela autora verificamos a quase inexistência de documentos actuais sobre o tema Trabalho Doméstico. Por outro lado, Bridget Anderson parece ser o nome mais focado pelos outros autores contemporâneos.

Ainda na área da sociologia podemos citar o nome de Elizabeth Beck, que se debruça fundamentalmente nas áreas da imigração, das comunidades e movimentos sociais, trabalho social com ênfase na justiça resolutiva e na pena de morte.

Esta autora realizou um estudo sobre trabalhadoras domésticas (Beck, 2001), numa perspectiva voltada para os movimentos sociais e imigração, baseando-se da Nacional Domestic Workers Union, uma importante associação espontânea de trabalhadores domésticos. 
Para além da área da sociologia, encontramos ainda um autor que merece ser aqui destacado por ter uma vasta obra no domínio do trabalho doméstico. Jeffrey Cole é formado na área de Antropologia e as principais áreas de interesse a raça, o domínio da política, como também, as questões ligadas à agricultura, alimentação, trabalho doméstico no quadro da imigração (Cole, 2006) e, por último, o tráfico humano. Autor de algumas obras sobre o trabalho doméstico em geral, foca essencialmente aspectos relacionados com a imigração e agricultura, sob um ponto de vista antropológico, como é o caso de uma das obras mais recentes, escrita em parceria com Sally Booth (formada na mesma área) (Cole, Booth, 2006). Uma das principais referências deste autor é Bridget Anderson.

Rina Cohen é outra autora que dedicou grande parte do seu trabalho à análise dos trabalhadores domésticos. Actualmente é professora na Faculty of arts, departamento de Sociologia, da Universidade York, em Toronto. Cohen tem desenvolvido um trabalho importante em diversas áreas de investigação: estudos feministas, sociologia da família, métodos qualitativos, etnicidade e migração, psicologia social, divisão do trabalho na família, relações de género, imigração feminina, etc. actualmente, tem vindo a desenvolver um trabalho sobretudo no campo das políticas de imigração, trabalho doméstico (Cohen 1991), identidade étnica das crianças dos imigrantes, teoria e metodologia feminista e etnografia.

Por fim, podemos ainda citar o nome de Annie Dusseuet (Dusseuet, 1999) que tem realizado um importante trabalho no campo da investigação do trabalho doméstico. Socióloga, actualmente na Universidade de Nantes, tem dedicado especial atenção ao estudo da articulação entre espaço público e espaço privado. O desenvolvimento do emprego na área de serviços domiciliares e o papel das mulheres neste desenvolvimento têm sido os temas mais abordados pela autora, destacando o importante papel das organizações associativas.

Estes são alguns dos principais autores que estudaram o trabalho doméstico enquanto categoria profissional. Na maior parte dos casos, o trabalho doméstico é estudado no quadro de outros domínios estudados. De certa forma, o que tornou o trabalho doméstico visível aos olhos de análises científicas foi justamente o facto de se cruzar com outros fenómenos sociais que garantem já um ser alvo variados estudos, ao longo dos anos, como o da imigração e violação dos direitos humanos. 


\section{APROXIMAÇÃO TEÓRICA AO CONCEITO DE TRABALHO DOMÉSTICO}

O trabalho doméstico aparece frequentemente referenciado no contexto da divisão sexual do trabalho, por ser precisamente um elemento central neste tipo de abordagem. No quadro de uma teoria biologista, a composição biológica dos sexos é apontada como ponto de partida para a formação de duas identidades distintas onde as diferentes percepções da realidade desencaminham o principal quadro de diferenciação entre os dois géneros. Ao mesmo tempo que servem de primeiro impulso à diferenciação, as diferenças biológicas legitimam uma identidade social que não pode ser evitada, materializando-se nomeadamente num processo de divisão social das tarefas.

Este processo inicial de diferenciação desencaminha todo o esquema de divisão de tarefas na vida quotidiana dando origem à dualidade entre produção (homem) e reprodução (mulher); esta é a primeira linha divisória que irá encaminhar a mulher para o círculo da reprodução onde as expectativas se projectam em torno do papel social de mãe, mulher e dona de (e não da) casa.

A divisão do trabalho sexual acabou por se instituir enquanto parte da divisão social do trabalho passando a ser observada ao mesmo nível da divisão existente entre trabalho intelectual e manual ou, numa perspectiva mais ampla, da divisão internacional do trabalho. Assim, a divisão sexual do trabalho, no fundo, não existe enquanto tal mas sim enquanto produto desta relação social antagónica entre os dois géneros. ${ }^{3}$

A divisão sexual do trabalho envolve dois campos de acção divergentes: a esfera do "privado" que, no seu âmago, é tida como oposta ao mundo do trabalho assalariado, e que se estrutura através de laços afectivos, emocionais e sentimentais. Esta divisão sexual do trabalho, que aponta para a dualidade entre produção e reprodução foi alvo de debate nos anos $70^{4}$ quando se colocaram questões que estiveram na base da noção de produção capitalista referida por Frederich Engels ${ }^{5}$. Algumas teorias feministas apontavam para uma definição de trabalho doméstico que se consolidava enquanto uma forma de produção, dada a importância do seu contributo na produção dos bens humanos que promovem a força de trabalho.

\footnotetext{
${ }^{3}$ Drew, Eileen, Ewerek, Ruth e Mahon Evely, (1998).

${ }^{4}$ Anderson, Bridget (2001), vol. 9, Issue 1, pp. 25-33.

${ }^{5}$ Engels, F. (1970) .
} 
Segundo Bridgest Anderson ${ }^{6}$, este foi um dos aspectos mais relevantes que foram discutidos nesta época, legitimando uma concepção do trabalho doméstico enquanto actividade produtiva. Na opinião de algumas feministas o trabalho doméstico é, assim, um trabalho produtivo e incide na produção de "seres humanos", no sentido de estabelecer as condições necessárias, na vida privada do lar, para que estes possam de facto contribuir com a sua força de trabalho, no seio da sociedade.

Uma outra particularidade relevante deste trabalho é que este se realiza num espaço geograficamente delimitado, no seio da vida privada, o que vai determinar formas diferentes de produção; neste espaço, o trabalho não é regulado pelo Estado nem pelo mercado e encontra-se inserido num sistema hierárquico dominado pelo sexo masculino. O mundo assalariado, também ele delimitado embora de forma mais ampla, é tido como o único modo de produção efectiva, legitimada por um mundo material em que as acções são estipuladas através de contratos, limitando as relações sociais tidas num determinado campo laboral.

O paradigma da divisão sexual do trabalho encontra-se, desta forma, interiorizado pelos indivíduos. As diferentes percepções acabam por delimitar os campos de acção. Por exemplo, a conotação de virilidade associada ao trabalho masculino é só por si um impedimento à ligação nestas duas esferas, assistindo-se, desta forma, a uma ruptura entre o trabalho assalariado e o trabalho doméstico que persiste nos nossos dias.

Esta descontinuidade acaba por não acontecer no campo das mulheres. Inicialmente permaneciam em casa sendo este o seu único trabalho, atribuído de forma automática, natural e por isso inquestionável. Este trabalho, por si só, era desvalorizado por ser visto à margem do trabalho assalariado, como não produzindo um bem material visível aos olhos da sociedade capitalista.

As mulheres percorrem, desta forma, todo um trajecto de acumulação de tarefas e não de substituição ou ruptura de algumas; um processo contínuo onde a igualdade entre os géneros não se verifica. Assiste-se, desta forma, nas palavras de Kergoat ${ }^{7}$, a um paradigma estruturado à volta dos conceitos “continuidade/ruptura” que permite avançar sobre argumentos de natureza sociológica nos debates à volta da subjectividade e da individualização.

Todo o conceito de trabalho doméstico engloba uma série de pré-noções que o identificam enquanto actividade e rotulam as pessoas que exercem as tarefas inerentes a este. Para além de

\footnotetext{
${ }^{6}$ Anderson, Bridget (2001).

${ }^{7}$ Kergoat, Danièle, “La division du travail entre les sexes” in Kergoat, Jacques, (1998). 
ser parte de uma categorização da individualidade feminina, o trabalho doméstico é, como já foi referido, e parafraseando Schwartz Cowan ${ }^{8}$, uma actividade onde se desenvolvem um conjunto de tarefas destinadas às classes mais baixas, estando, por isso, associadas a um baixo estatuto. $\mathrm{O}$ trabalho doméstico existe, assim, como forma de diferenciação e caracterização das classes sociais.

\subsection{Trabalho Doméstico e Trabalho Doméstico Remunerado}

Torna-se, desta forma, imprescindível traçar a fronteira que existe entre trabalho doméstico e trabalho doméstico assalariado. A história do trabalho doméstico descreve, em primeiro lugar, a concretização do trabalho doméstico não remunerado; a transição para o trabalho doméstico remunerado não foi realizada de forma naturalmente progressiva, enquadrando devidamente o trabalho doméstico num outro contexto em que a realização deste trabalho é feita, normalmente por indivíduos exteriores ao núcleo familiar. Assiste-se sim, a um crescimento do trabalho doméstico não pago, que se realiza no núcleo familiar e que apenas se transforma em trabalho doméstico remunerado devido ao crescimento demográfico, bem como a outras variáveis que serão tidas em conta, posteriormente, no presente relatório. Assim sendo, a barreira entre trabalho doméstico e trabalho doméstico remunerado foi, muitas vezes, fonte de algumas polémicas entre os especialistas que se debruçam sobre este assunto.

Para Mary Clarke ${ }^{9}$ o trabalho doméstico pago distingue-se justamente, como o próprio nome indica, pelo facto de este ser remunerado e por normalmente ser executado por trabalhadores domésticos contratados para executarem as tarefas domésticas em casa de outra pessoa (singular ou não).

No fundo, em termos de execução de tarefas, este trabalho acaba por não sofrer alterações e basicamente abrange as seguintes tarefas: lavagem e tratamento de roupas, limpeza e arrumo da casa, confecção dos alimentos, vigilância e assistência a crianças, pessoas idosas e doentes, jardinagem, tratamento de animais domésticos, execução de serviços de costura e outras actividades consagradas pelos usos e costumes que estejam relacionadas com o $\operatorname{lar}^{10}$; as alterações que se verificam estão centradas na pessoa que pratica a actividade e na forma como a pratica uma vez que não é o proprietário do espaço onde executa as suas tarefas provocando um maior distanciamento face ao que é produzido. Por outro lado, apesar de ser uma pessoa

\footnotetext{
${ }^{8}$ Schawartz Cowan, R. (1983).

${ }^{9}$ Clarke, Mary P. (2002).

${ }^{10}$ Decreto-Lei no 235/92, de 24 de Outubro.
} 
“exterior” a realizar este trabalho, na esfera da vida privada, ao abrir as portas a uma empregada doméstica inicia-se, necessariamente, uma diferente forma relacional, que implica um grau elevado de intimidade e confiança, inexistente noutro campo laboral, não deixando, no entanto de ser uma actividade laboral que exige regulamentação e salário.

O facto da fronteira existente entre trabalho doméstico e trabalho doméstico remunerado estar mediada por um salário poderá, de certa forma, dissipar a verdadeira natureza do trabalho doméstico, como refere Bridgest Anderson ${ }^{11}$. De facto, o trabalho doméstico remunerado não poderá ser visto da mesma forma que o trabalho doméstico não pago, uma vez que estamos a falar de uma relação laboral que, embora realizada no campo de uma esfera privada, concentra em si a especificidade de ser remunerada, e de ganhar, com isso, um novo enquadramento dentro do mercado de trabalho, bem como, no campo das profissões. Para além disso, o trabalho doméstico da mulher no seio da vida familiar podia ser visto como forma de demonstrar afecto e cuidado; uma vez remunerado e realizado por uma pessoa exterior à família em questão, o trabalho doméstico não pode revestir o mesmo significado.

\subsection{Alguns aspectos sobre a Remuneração no Trabalho Doméstico}

O trabalho doméstico, enquanto trabalho remunerado, é caracterizado por uma informalidade não só pela flexibilidade dos horários e pela própria mobilidade do trabalhador face à estrutura laboral, como também em termos salariais, no sentido em que não existe uma pré-definição de preços.

Para Anderson ${ }^{12}$ torna-se difícil de encontrar um valor que pudesse ser justo no quadro desta relação laboral, uma vez que não se está a lidar com coisas materiais, mas sim com pessoas interferindo, inevitavelmente, com o campo dos sentimentos.

Esta relação laboral é assim marcada por laços de dependência afectiva que podem colidir com a noção de trabalho no seu sentido mais lato. Isto acontece por estarem em causa dois campos distintos, a esfera da vida privada e a esfera do campo laboral.

A trabalhadora doméstica ocupa, por vezes, um papel importante no seio da família, sobretudo se algumas das suas tarefas passam por cuidar de algum membro da mesma; nesta situação a relação laboral tende a passar para uma relação afectiva, onde se criam laços de dependência.

\footnotetext{
${ }^{11}$ Anderson, Bridget (2001) pp. 25-33.

${ }^{12}$ Anderson, Bridget (2001), pp. 25-33.
} 
Quando esta relação é próxima, segundo alguns autores, existe um constrangimento face à remuneração que é atribuída à trabalhadora doméstica. As regalias e outros benefícios são a forma encontrada para tentar ultrapassar este tipo constrangimento.

Esta questão da afectividade é pertinente no quadro da relação contratual que se estabelece entre a trabalhadora e o patrão, uma vez que não se encontra explícita mas acaba por interferir nas várias dimensões económico-jurídicas de um contrato formal.

O facto do trabalho doméstico estar inserido na esfera privada de uma família implica um modo de produção diferente do que se verifica noutros campos da sociedade; trata-se aqui de indivíduos e não de um produto, trata-se se relações laborais que acabam por se confundir com relações interpessoais de cariz mais intimo. A trabalhadora fica a conhecer toda a rotina diária dos patrões e todos os meandros da esfera privada de uma família, onde inevitavelmente acaba por fazer parte desta. (Dill, Kousha, Rollins). ${ }^{13}$

Assiste-se aqui de uma espécie de produção de valores culturais e representações sociais, diferente da mera produção de comodidades para a vivência do ser humano. Como consequência disso, o trabalho doméstico acaba por estar envolvido na importante tarefa de preservar os aspectos físicos que se interligam com aspectos emocionais íntimos. O trabalho doméstico contribui para o desenvolvimento da cultura e de hábitos de vida na esfera privada que se reflectem necessariamente na esfera pública da sociedade.

Estas particularidades do trabalho doméstico motivam a convicção que Anderson ${ }^{14}$ tem ao afirmar que o trabalho doméstico não é apenas mais um trabalho pago e que difere de outras formas de trabalho pago pela sua própria natureza, implicando um relacionamento contratual complexo, por envolver não só uma força de dominação sobre o trabalhador como também a sua própria identidade pessoal.

\subsection{Regimes Laborais no Contexto do Trabalho Doméstico}

A informalidade atribuída ao trabalho doméstico passa não só pelo campo da remuneração em si mas também, e sobretudo, pela autonomia e informalidade nos regimes que implica. A trabalhadora doméstica pode ter um ou vários patrões e estar inserida num ou em vários regimes diferentes. A fim de dar conta da especificidade das diversas estruturas que o trabalho

\footnotetext{
${ }^{13}$ Dill, B. (1994).

${ }^{14}$ Anderson, Bridget (2001), pp. 25-33.
} 
doméstico projecta é pertinente ter em conta um estudo realizado por Mary Clarke ${ }^{15}$, onde se identificam três regimes distintos que se adequam as formas laborais do trabalho doméstico que tendem a persistir nas sociedades contemporâneas: o trabalho interno, não interno e trabalho em regime de part-time.

O trabalho interno caracteriza-se pelo facto do trabalhador doméstico viver em casa do patrão; ambiente favorável à evolução de uma relação caracterizada por uma maior dependência e intimidade. Este contexto é propício a que haja um desrespeito face às horas de trabalho e horas de descanso da trabalhadora.

O trabalhador não interno distingue-se sobretudo por ter horas de trabalho estipuladas, sendo que no término destas regressa para sua casa. Neste caso, a relação laboral é caracterizada por uma maior autonomia da trabalhadora face ao patrão, deixando de ser tida como "propriedade" do mesmo, podendo até ter vários locais de trabalho e diversos patrões.

Por último, e mais recentemente, o regime de part-time. Neste caso, as horas e os dias são estipulados, a trabalhadora apenas trabalha alguns dias ou algumas horas durante um dia; este regime enfraquece os laços de proximidade e dependência, abrindo as portas a um maior distanciamento e maior autonomia da trabalhadora face ao seu patrão.

Estes regimes laborais tendem a permanecer nos nossos dias. A escolha de qualquer um destes regimes irá ser feita de acordo com as funções que se pretende dar à trabalhadora. Apesar de ser ainda prematuro tirar conclusões acerca disso, poderá existir uma relação entre as funções desempenhadas, a responsabilidade que as mesmas implicam, e o regime laboral em que se pretende contratar a trabalhadora doméstica.

Assim, a necessidade de se contratar trabalhadoras domésticas em regime de serviço interno terá a ver com a quantidade de tarefas que se pretendem realizadas e/ou com a responsabilidade que estas implicam como, por exemplo, cuidar de uma criança ou de um idoso.

O mesmo acontecerá no caso do regime a part-time que fundamentalmente terá como objectivo a realização de pequenas tarefas domésticas, consideradas básicas, cuja sua produção se torna imprescindível aos olhos de quem contrata a trabalhadora doméstica. O regime a part-time

\footnotetext{
${ }^{15}$ Clarke, Mary P. (2002), 51: 4.
} 
também poderá ter a ver com a economia familiar no sentido de não se pretender ou não se poder dispensar muito do orçamento familiar com a contratação de trabalhadoras domésticas.

Apesar destas relações laborais parecerem estar delineadas não podemos deixar de verificar uma certa informalidade nas mesmas, ou seja, a trabalhadora doméstica enquadra-se num sistema de trabalho anárquico no sentido em que aparentemente se assiste a uma grande flexibilidade na mobilidade de um regime para outro ou na junção de regimes.

Assim, a trabalhadora doméstica poderá ter vários trabalhos, em diferentes locais, estar em regime de part-time, ou estar num regime não-interno e trabalhar ao fim-de-semana em parttime, conjugando, desta forma, dois regimes laborais.

Esta informalidade no trabalho doméstico irá ser um ponto de partida para a investigação que se pretende efectuar, desta forma este será um tema a ser desenvolvido posteriormente, no decorrer da investigação.

\subsection{Variáveis que influenciaram o fluxo crescente da procura de trabalhadoras domésticas}

O trabalho doméstico remunerado tem-se revelado ser uma prática domiciliária, em crescimento, em todo o mundo. E é precisamente neste domínio que se pode analisar uma novas formas de relacionamento entre as mulheres onde conceitos de dominação e subordinação tendem a ganhar um novo registo. Como já foi aqui referido, são maioritariamente mulheres a desempenharem este tipo de funções e, de igual forma, são geralmente mulheres que comandam estas mesmas funções, por motivos de herança cultural e social. As mulheres tendem a contratar outras mulheres para desempenhar funções às quais continuam a estar destinadas; apesar disso não se pode dizer que existe aqui uma ruptura nas tarefas, uma vez que, de forma geral, continua a ser a mulher a coordenar as mesmas funções.

Com o constante desenvolvimento das sociedades e com a emancipação da mulher para o mercado de trabalho, verificamos um acréscimo global na contratação de empregadas domésticas; um fenómeno que, inicialmente, poderia ser sinónimo de luxo característico de uma elite, passa a verificar-se em quase todas as classes sociais.

A procura de trabalhadores domésticos não se encontra hoje tão associada ao nível sócioeconómico da família, mas representa a necessidade que a família sente em procurar recursos 
exteriores capazes de oferecer benefícios para a execução das tarefas domésticas no quotidiano familiar.

O envelhecimento da população e o aparecimento cada vez maior de famílias nucleares são dois factores que influenciam a taxa relativa ao número de trabalhadoras domésticas. Os países onde se verifica um maior aumento de mulheres no mercado de trabalho são, consequentemente, países onde a taxa de trabalhadoras domésticas também aumenta; fenómeno que não deixa de estar interligado com fenómeno migratório campo-cidade e com o acréscimo verificado na economia familiar, proveniente do ordenado da mulher.

Alguns autores defendem que o crescimento da procura de trabalhadoras domésticas não só tem a ver com a entrada das mulheres no mercado de trabalho e com o consequente crescimento da economia familiar, mas também, com o facto da esperança média de vida ter aumentado e ser necessária uma constante procura de trabalhadoras domésticas para determinadas funções que exigem outro tipo de responsabilidades, tal como, cuidar de idosos.

Assistimos, assim, a uma crescente procura de trabalhadoras domésticas num mercado em que o trabalho doméstico parece ser, em vários países, a oportunidade rápida e instantânea de oportunidade de trabalho e inserção social para imigrantes. Daí que, nos nossos dias, a maior parte das trabalhadoras domésticas sejam imigrantes; o trabalho doméstico para esta população constitui uma porta aberta para a inserção social e uma boa alternativa para fugir a outros tipos de trabalho, tais como a prostituição. 


\section{TRABALHADORAS DOMÉSTICAS: PERFIL E TRAJECTÓRIA SOCIAL}

A análise do trabalho doméstico não exclui uma cuidada avaliação do perfil social da trabalhadora doméstica e da forma como este grupo é categorizado. Assim, as suas práticas e hábitos da trabalhadora doméstica, no contexto laboral, acompanharam algumas transformações culturais e sociais que, ao longo dos anos, se fizeram sentir sobretudo no domínio da família, migrações e economia.

Se recuarmos um pouco no tempo verificamos que, inicialmente, as trabalhadoras domésticas eram jovens solteiras, provenientes das classes mais baixas, que trabalhavam em troca de um rendimento mensal baixo, de um pequeno quarto e alimentação sendo, por isso caracterizadas como empregadas domésticas internas que permaneciam em casa dos seus patronos até casar.

No final da I Guerra Mundial, o mercado de trabalho abriu novos postos de trabalho para as mulheres. Uma crescente vaga de imigração para os Estados Unidos influenciou, de igual forma, algumas transformações no mercado do trabalho doméstico. Por esta altura, este mercado de trabalho foi invadido pelos imigrantes que, de forma crescente, foram empurrados para estes postos de trabalho.

Nesta fase, os trabalhadores domésticos continuavam a ser maioritariamente mulheres, provenientes do Norte de África, que trabalhavam em casa de burgueses. Estas mulheres eram geralmente, e contrariamente ao que se verificava antes, casadas pelo que preferiam não ser internas. Esta nova forma de organização do trabalho alterou as relações laborais em que foi cedido uma maior autonomia à trabalhadora doméstica, acabando por romper com qualquer conceito de escravidão que, anteriormente, se encontrava associado a esta categoria profissional.

Hoje, a tendência continua a ser a mesma: as trabalhadoras domésticas continuam a ser maioritariamente mulheres, oriundas das classes mais baixas e, na maior parte dos casos, imigrantes.

Como é conhecido, os fluxos migratórios prendem-se com causas de ordem económica. Apesar disso, o artigo publicado por Anderson ${ }^{16}$ demonstra que a violência doméstica pode ser outro factor determinante no fluxo migratório de mulheres. Em qualquer um dos casos a principal preocupação do imigrante ao chegar ao país de destino é encontrar trabalho para garantir a sua

\footnotetext{
${ }^{16}$ Anderson, Bridget (2001), pp. 25-33.
} 
subsistência. Desta forma, os imigrantes são facilmente impelidos para o trabalho doméstico ou outros trabalhos caracterizados por um baixo estatuto sócio-económico.

Após garantirem alguma estabilidade do ponto de vista financeiro, todos os esforços concentram-se na tentativa de enviar dinheiro para familiares que tenham ficado no país de origem. Esta contribuição económica, por parte da mulher, não deixa de ter o seu impacto nas relações de género mesmo que não tenham consciência disso, ou que este factor não lhe seja reconhecido.

Assiste-se, hoje em dia, a um fluxo crescente de imigrantes em situação irregular. Aparentemente esta condição parece não ser um obstáculo no processo de inserção no mercado do trabalho doméstico, sendo que existem indícios que a não realização de um contrato de trabalho não é vista como um impedimento mas poderá até ser tida como um benefício para ambas as partes, embora seja uma situação de risco para a trabalhadora doméstica que permanece à margem de qualquer tipo de protecção, face ao trabalho e face ao patrão perante o qual se encontra numa relação de dependência.

A crescente inserção de imigrantes no mercado de trabalho doméstico contribuiu para uma categorização do perfil destas trabalhadoras, consolidando-se um estereótipo, onde a raça passa a fazer parte da rotulagem. Um estereótipo que vai contribuir para a emergência de factores discriminatórios, que vão constituir obstáculos na trajectória social das trabalhadoras domésticas.

Os rótulos, assim, são construídos no seio da sociedade, como forma de abrir as portas a uma categorização que vai modelar a percepção de uma dada realidade; são apreendidos através dos mais diversos inputs que se estabelecem no ninho social, delimitando as acções sociais no sentido de impor uma resposta a uma determinada expectativa. Hill Collins ${ }^{17}$ fala da associação que a dada altura se estabeleceu em torno das amas, imagem rotulada de bondade e obediência, cultivada aquando da estreia do filme "Música no Coração” que teve grande impacto em vários países. Esta associação acabou por dar origem a uma noção do que seria um tipo ideal de trabalhadora doméstica, enquanto pessoa responsável e perfeita no desempenho das suas tarefas, contribuindo, desta forma, para a criação de expectativas elevadas face a esta categoria profissional.

\footnotetext{
${ }^{17}$ Hill Collins, P. (2000), citado por Beck, Elisabeth, (2001). 
Apesar da invisibilidade do trabalho doméstico, denunciada por uma desvalorização do mesmo, as tarefas que lhes estão subjacentes são alvo de constantes apreciações por parte de quem o avalia, onde o grau de exigência valoriza a perfeição das tarefas desempenhadas. Isto acontece em parte pela responsabilidade que está inerente a estas tarefas, uma vez que se trata de cuidados do lar e da casa e interfere com a intimidade de outra pessoa, e também por estas tarefas serem, geralmente, avaliadas por outra mulher que, por uma evidência cultural, adquire a legitimidade de ser vista enquanto especialista na matéria.

Após uma sucinta referência ao perfil e social da trabalhadora doméstica torna-se essencial focar determinados aspectos relativos à trajectória da trabalhadora, no quadro da relação laboral.

Uma vez que o trabalho doméstico tem a particularidade de se situar na esfera privada, torna-se pertinente reflectir sobre as relações laborais que se estabelecem neste campo e, desta vez, centrando uma particular atenção sobre quem e de que forma se executa este tipo de trabalho.

\subsection{Relações Laborais e Estratégias das Trabalhadoras Domésticas}

Para Bridget Anderson, o conceito de trabalho doméstico abrange um conjunto de relações interpessoais, num local geograficamente delimitado, que determinam um determinado status social. É precisamente neste conjunto de relações interpessoais que devemos agora centrar a nossa atenção.

Como já foi referido, sendo o trabalho doméstico um campo laboral com determinadas especificidades que o distinguem de outros contextos laborais, devemos ter em conta este contexto específico para podermos desenvolver uma análise das relações laborais no trabalho doméstico.

Apesar de ser realizado no seio de um lar e da relação entre trabalhadora doméstica e patrão ser caracterizado, por vezes, por uma grande intimidade, não podemos excluir a noção de que o trabalho doméstico traduz sempre uma relação de dominação face à trabalhadora sendo esta percepcionada enquanto “outro”.

Este estatuto de "outro" deve-se ao facto da trabalhadora doméstica ter o papel primordial de promover o conforto de quem a contrata, sendo que neste processo o campo sentimental e humano mantém-se à margem de qualquer consideração por parte do empregador. 
A teoria do "Othering” implícito no estudo sobre trabalhadoras domésticas é referida na obra de Rollins ${ }^{18}$, quando identifica um relacionamento maternal entre trabalhadoras e patrão. Este autor explica que este maternalismo se materializa numa dupla perspectiva: proteger e alimentar, mas também, degradar e insultar.

As tarefas desempenhadas pela trabalhadora doméstica acabam por ser a base para esta teoria maternal; todas estas funções traduzem-se em cuidados face a um ou vários indivíduos, sendo que esta actividade não se encontra livre de projectar sentimentos e afectos de parte a parte. Assim sendo, a natureza destas funções garantem, por outro lado, uma intimidade maior na relação onde se verifica a necessidade que o patrão tem de acolher o trabalhador enquanto "parte da família”.

É neste contexto de relações interpessoais que se podem encontrar respostas a diversas atitudes que alguns autores identificaram ao longo da realização de estudos sobre trabalhadoras domésticas.

O trabalho doméstico é um campo de divergências culturais cada vez mais acentuadas pelo facto da junção de diferentes hábitos e estilos de vida, tornando-se a capacidade de adaptação um desafio constante. Sobre este assunto podemos referir alguns aspectos que foram sublinhados num estudo realizado entre 1984 e 1986, por Cohen ${ }^{19}$. As conclusões a que chegou foram retiradas a partir de dados recolhidos através de entrevistas realizadas a mulheres africanas que trabalhavam em casa de particulares no Canada há, pelo menos quatro anos.

Foi observada uma regularidade, nas estratégias adoptadas pelas trabalhadoras domésticas no meio laboral, que deu origem a quatro tipos de acção definida pela autora. Um primeiro tipo, denominado "external power resources" reage ao isolamento habitualmente provocado pelo trabalho doméstico. Este isolamento é sobretudo verificável no contexto de um regime de trabalho a tempo inteiro onde a trabalhadora é interna.

No esforço de adaptação que esta realidade implica, a solidão provocada pelo isolamento e pela adaptação a um diferente contexto social, impulsiona a necessidade de procurar outros laços

\footnotetext{
${ }^{18}$ Rollins, J. (1985), Between women: domestics and their employers. Philadelphia: Template University Press, citado por Beck, Elizabeth, (2001) volume XXVII, nº 4.

${ }^{19}$ Rina Cohen, (1991), vol. 14, $n^{\circ} 2$.
} 
sociais, exteriores ao local de trabalho, que permitem consolidar um processo de identificação que possa ultrapassar o sentimento de isolamento vivido no contexto laboral.

A autora identificou a necessidade, por parte da trabalhadora, em procurar pessoas que, de alguma forma, projectam hábitos e culturas semelhantes ou que, muito simplesmente se encontram na mesma posição; condição determinante para a emergência de um conjunto de práticas que possam colmatar o vazio provocado pela ausência de coesão social.

Para além da família, onde a relação é frequentemente alimentada por meio de telefonemas ou cartas, a igreja é um local privilegiado não apenas para a obtenção de apoio moral e espiritual mas, sobretudo, por ser um local frequentado por muitos trabalhadores que se encontram na mesma situação. A necessidade de integração num grupo ao qual podemos chamar de identificação atrai as trabalhadoras para locais onde possam estabelecer relações com pessoas às quais se identificam por também serem imigrantes e exercerem a mesma profissão.

Em muitos países, os imigrantes são, de certa forma, empurrados para o trabalho doméstico, sendo este um dos únicos recursos para conseguirem sobreviver no país de destino. Ao entrar no trabalho doméstico a ilusão de ser um trabalho temporário acaba, muitas vezes, por ser substituída pela frustração de estar dependente do mesmo.

A rede de relações sociais externas acaba por adquirir uma extrema importância na trajectória de vida da trabalhadora, assistindo-se, desta forma, a uma crescente intensificação das mesmas com tendência para se transformar em algo próximo de uma estrutura familiar. Se, por um lado, este grupo de pertença ajuda a solidificar laços dentro do próprio grupo por outro, intensifica crescimento da consciência da sua situação traduzindo-se num maior distanciamento face ao outro grupo.

É neste contexto que a autora identifica determinados comportamentos que traduzem este distanciamento, exemplo disso é o uso recorrente a piadas construídas com base em episódios da vida íntima dos patrões. Este hábito funciona também como forma de aproximar e unir o grupo de pertença face a este grupo de referência.

A autora refere ainda um segundo tipo que designa de "Internal power resources": traduz-se numa prática frequente que os patrões têm em oferecer prendas às trabalhadoras como forma de compensar a baixa remuneração. O facto da trabalhadora ter consciência da sua situação precária provoca não só a aceitação desta prática, como pode causar a sua maior frequência. 
A regularidade de determinados comportamentos no seio da relação laboral conduz à formação de mais um tipo de reacção que consiste num decréscimo na produção por parte das trabalhadoras domésticas. Segundo a autora, este fenómeno pode ser explicado, em parte, pela troca de informação que estimulado no seio do grupo de pertença e que se constitui numa maior consciencialização face à sua condição.

A autora verificou que, inicialmente, se assiste a um esforço maior, por parte das trabalhadoras, em satisfazer os patrões, exigindo um esforço maior no desempenho das suas funções. Esta motivação tem a tendência para decrescer de forma gradual ao longo do tempo. Este desinteresse pode ser, em parte, justificado pela falta de reconhecimento do seu esforço por parte do patrão e, consequentemente, por uma falta de motivação.

As trabalhadoras arranjam vários argumentos para justificar o decréscimo de produtividade. Por exemplo, a consciencialização do estereótipo que lhes é atribuído é usado a favor do seu decréscimo nas tarefas, exemplo disso é a "preguiça”, enquanto característica normalmente associada às trabalhadoras domésticas. Não existe assim tendência para contrariar ou desmistificar o estereótipo mas sim reforçá-lo através de atitudes. Um outro exemplo disso traduz-se no facto de poder ter alguma tarefa prioritária, estipulada pelo patrão (como, por exemplo, cuidar de uma criança) e servir-se deste facto para a não realização das restantes tarefas impostas.

Por último, a autora identifica um outro tipo de reacção, “cognitive alteration”, que se traduz num exercício psicológico que o trabalhador pratica com o intuito de ultrapassar o sentimento de inferioridade e subordinação. Tal como já foi referido neste documento, a maior parte das trabalhadoras revelam ter o desejo de trocar de profissão, daí encararem este trabalho como algo provisório. Inicialmente, para conseguirem emprego admitem utilizar uma "máscara” para poder esconder alguma característica que possa ser prejudicial para a fase de selecção. Geralmente são traços de personalidade que, de alguma forma, irão o contra um ideal-tipo da trabalhadora doméstica.

Uma vez que tenham conseguido o emprego, a relação de subordinação e sentimento de inferioridade face aos patronos são colmatados interiormente e expressos através de pequenos actos escondidos; estes pequenos actos caracterizam-se como pequenas vinganças que, por vezes, são realizadas no decorrer das tarefas domésticas. O tal humor implícito nas narrações de pequenos episódios da vida dos patrões é justamente um acto não só de distanciamento, como 
verificamos atrás, mas também, segundo a autora, uma defesa psicológica que tende a minimizar o sentimento de inferioridade face aos patrões.

No fundo, a liberdade de expressão e relativa liberdade de acção cedida aos trabalhadores domésticos são parte integrante de um espaço individual onde as acções têm como principal objectivo minimizar e ultrapassar, ilusoriamente, laços de subordinação existente nestas relações laborais, emergindo um sentimento de controlo sobre o patrões.

\section{RESPOSTAS ASSOCIATIVAS E GOVERNAMENTAIS}

Ao longo deste relatório preliminar verificamos que existe uma tendência crescente para a junção de trabalhadores domésticos em associações impulsionada pela necessidade de coesão social e, sobretudo, pela necessidade de dar visibilidade a este trabalho. Estas associações existem um pouco por todo o mundo e, com o desenvolvimento das novas tecnologias, encontramos novos espaços para uma maior proliferação desta prática tendo novos mecanismos de transmissão de informação como, por exemplo, a Internet.

Apesar de ainda não ter sido feito uma avaliação intensiva destas associações é importante referir alguns exemplos, dados por alguns autores, a fim de perceber a estruturação deste tipo de ajuntamento.

Na grande maioria dos casos, estas associações espontâneas transformam-se em organizações mais estáveis que têm como objectivo sensibilizar as estruturas governamentais no sentido de promover leis e outras medidas benéficas à protecção das trabalhadoras domésticas e à regulação do trabalho doméstico.

No estudo realizado por Bridgest Anderson ${ }^{20}$ sobre trabalhadoras domésticas Filipinas em Londres refere-se o nascimento de uma destas associações e a evolução que teve ao longo dos anos, funcionando como uma força conjunta rumo à organização de uma estrutura mais sólida em termos de funcionamento, com a adopção de algumas estratégias e objectivos definidos.

Esta associação evoluiu e fortaleceu-se ao longo dos anos até conseguir ter uma sede num edifício situado em Londres. Lugar baseado na UE para o desenvolvimento do trabalho doméstico imigrante na Europa, RESPECT. Esta iniciativa partiu da UWA (United Workers' Association) que acabou por se definir enquanto organização política destinada a acompanhar e

\footnotetext{
${ }^{20}$ Bridgest Anderson, (2001), p673-683, 11p.
} 
traçar o caminho dos direitos das trabalhadoras domésticas imigrantes, independentemente do seu status e da sua própria regularização.

O estudo supracitado é apenas um exemplo da forma como estas organizações surgem. As dificuldades sentidas pelos imigrantes no processo de integração no país de destino mas, sobretudo, a necessidade de agir perante a violação dos seus direitos são as principais motivações que se encontram por detrás desta iniciativa.

Um outro exemplo que merece ser, aqui, referido é de uma união de trabalhadoras domésticas, que foi instituída na década de sessenta, e é referenciada na obra de Elizabeth Beck ${ }^{21}$. Esta união foi criada por Dorothy Bolden e é denominada de National Domestic Workers Union, consagrando os principais objectivos que já foram aqui referidos, característicos deste tipo de movimentos, a NDWU parece permanecer, ainda nos nossos dias, como exemplo para muitas destas associações.

Estes movimentos transformam-se, perante o recurso a diversos meios, em importantes locais de interacção onde a troca de informação é um instrumento primordial na prevenção de violação dos direitos das trabalhadoras. A Internet torna-se um recurso frequentemente utilizado para a difusão desta informação. Apesar disso, estas associações tendem a ter uma sede fixa para garantir uma melhor e maior aproximação face à população-alvo.

Numa análise ainda superficial dos sites destas organizações verificamos que existe uma preocupação crescente em informar a trabalhadora sobre os seus direitos, prevendo com isto, espaços onde se acumulam leis sobre imigração, bem como leis centradas em aspectos relativos aos contratos de trabalho, onde se encontram implícitos os direitos e deveres dos trabalhadores, assim como, dos empregadores. Uma das grandes preocupações é facilitar a obtenção de vistos e regularizar a situação da trabalhadora no país de acolhimento.

Nestes sites, onde a predominância de cores fortes é característica no apelo que se pretende projectar, encontram-se espaços para os relatos de algumas situações vividas pelas trabalhadoras assim como dúvidas que surgem e que automaticamente são respondidas pelos membros destas associações. Para além deste objectivo de carácter mais formal e informativo, as associações apostam na formação das trabalhadoras, insistindo em áreas que consideram ser prioritárias,

\footnotetext{
${ }^{21}$ Beck, Elizabeth, (2001).
} 
como o conhecimento da língua inglesa ou a formação mais especializada nalguma tarefa que frequentemente faz parte do quotidiano de uma trabalhadora doméstica.

Verifica-se, desta forma, a necessidade de profissionalizar o trabalho doméstico, com o principal intuito de conseguir um maior equilíbrio deste tipo de trabalho e o trabalho realizado no contexto económico-profissional, garantindo, desta forma, uma maior visibilidade no seio da sociedade.

Uma vez que a integração do imigrante no país de acolhimento é, como já foi referido, um dos objectivos propostos por estas associações existe um esforço para promover um conjunto de actividades de lazer que visam proporcionar não só uma mais fácil integração mas que, sobretudo, promovem uma melhor qualidade de vida.

Estas associações partem da necessidade de dar visibilidade e como tal, todas as iniciativas estão voltadas para que haja uma maior consciencialização por parte das trabalhadoras da sua condição precária, e, sobretudo, para que não sofram abusos por parte de quem as contracta. Estas associações lutam, de igual forma, para ser a voz das trabalhadoras domésticas e exigirem medidas governamentais de protecção social.

Um grande objectivo destas associações passa, ainda, por um esforço em reunir as condições necessárias para que sejam tomadas medidas que garantem a formação e especialização da trabalhadora doméstica, tentando, desta forma, legitimar o trabalho doméstico enquanto actividade profissional, afastando-o das pré-noções que o desvalorizam. Porém, segundo Anderson, esta medida poderá ter o efeito perverso no sentido em que poderá estar na origem de uma hierarquia dentro da própria categoria laboral, marginalizando as trabalhadoras domésticas ilegais.

A invisibilidade do trabalho doméstico é, sem dúvida, um grande obstáculo ao desenvolvimento da regulamentação desta matéria. O crescimento das associações espontâneas que se fazem acompanhar pelo desenvolvimento das novas tecnologias, significa uma importante força motora capaz de, como já foi referido, não só ser fonte de informação imprescindível às trabalhadoras domésticas, como também servir de espaço primordial para dar continuidade a um processo de combate a esta invisibilidade.

Os anos 90 foram marcados pelo desenvolvimento da comunicação internacional entre grupos associados de trabalhadores domésticos, como ficou registado nos dois exemplos referidos no 
presente capítulo. Estas organizações começaram a ter um local de eleição na Internet, quando em $1994^{22}$ a Home-net (international Network) foi organizada com o objectivo central de promoção e divulgação de informação e coordenação de um trabalho a nível internacional.

Com o apoio da OIT conseguiu-se um considerável trabalho na divulgação de informação através de newsletters e da publicação de boletins que permitiram divulgar dados relativos às organizações de trabalhadores domésticos espalhadas um pouco por todo o mundo.

Estas novas formas de agrupamento deverão também ser tidos em conta num trabalho de investigação que pretenda delimitar os meandros deste fenómeno social.

A legislação actualmente em vigor no nosso país contempla os deveres e direitos do(a) trabalhador(a) doméstico(a). Apesar de ser necessário confirmar esta informação, assistir-se-ia a uma descrença face à lei portuguesa o que, na prática traduz-se na não aplicação da lei, mantendo as trabalhadoras domésticas em situação irregular e, logo, desprotegidas. Apesar de prejudicial para a trabalhadora doméstica esta atitude parece ser aprovada e incentivada pela própria trabalhadora.

A nível internacional assiste-se já a esforços, por parte de alguns países, para dar alguma resposta no sentido de tentar ultrapassar as barreiras da invisibilidade do trabalho doméstico, e de regulamentar as condições em que este é realizado, com o intuito de preservar os direitos dos trabalhadores.

Em 2005 realizou-se um relatório a partir de uma Conferência Internacional organizada com a colaboração de três entidades principais: European Trade Union Confederation (ETUC), Internacional Restructuring Educational Network Europe (IRENE) e a Platform for International Cooperation on Undocumented Migrants (PICUM). Este relatório sublinha a necessidade de existir uma maior colaboração, por parte de associações de trabalhadores, ou qualquer outro mecanismo legítimo, no sentido de a relação entre trabalhador doméstico e empregador passar a ser objecto de uma melhor regulamentação.

Neste relatório efectuou-se o levantamento de medidas governamentais adoptadas por alguns países da UE que sentiram a necessidade de intervir na regularização do trabalho doméstico. Algumas leis foram elaboradas de forma a dar resposta à informalidade do trabalho doméstico.

\footnotetext{
${ }^{22}$ Drew, Eileen, Ewerek, Ruth e Mahon Evely, (1998).
} 
Apesar da frequência do trabalho doméstico nas sociedades contemporâneas, as medidas tomadas até hoje são ainda insuficientes para que se possa falar de uma resposta real e efectiva.

A especificidade do trabalho doméstico resulta justamente no facto de ser praticado na esfera privada da família, delimitação espacial onde normas e leis da esfera pública não se aplicam facilmente. Um possível esforço por parte de associações de trabalhadores poderia, de facto, ser útil nesta tarefa. Mas seria necessário estabelecer um organismo que representasse, também, o empregador, para que a mediação pudesse ser garantida de uma forma institucional, o que facilitaria o trabalho de regulamentação.

A globalização do trabalho doméstico induz a movimentação de diversas estruturas sociais na tentativa de adaptar, da melhor forma, novos mecanismos que poderão ou não retirar o pano da invisibilidade que recai sobre esta actividade profissional.

\section{CONCLUSÃO}

A emancipação da mulher, sua entrada no mercado de trabalho e consequente crescimento da economia familiar aparecem como principais factores de um crescimento na procura de trabalhadores (as) doméstico (as). Para além disso, o desenvolvimento das sociedades, o aumento da esperança média de vida, assim como o envelhecimento da população são factores determinantes para uma verdadeira evolução do mercado do trabalho doméstico.

Principalmente realizado por mulheres, este trabalho caracteriza-se como actividade das classes mais baixas, o que acarreta uma desvalorização do mesmo, e a sua invisibilidade social.

Com o constante fluxo migratório a que se assiste nos nossos dias, em diversos países, este tipo de trabalho atrai em muitos casos imigrantes, enquanto forma de subsistência no país de acolhimento. A imigração ilegal revela ser um problema acrescido na violação dos direitos dos(as) trabalhadores(as) domésticos(as) que se encontram numa situação de dependência face ao patrão. Panorama onde as associações espontaneamente criadas por estes(as) trabalhadores(as) poderão ter um papel de destaque na prevenção e protecção face a estas situações.

Num espaço único onde comungam a esfera da vida privada com as relações laborais, encontramos uma estrutura que merece ser estudada sob várias perspectivas científicas. A proximidade com o campo afectivo provoca algum desconforto nesta relação laboral e 
determina uma relação de dependência mútua que se estabelece entre o(a) trabalhador(a) doméstico(a) e o seu patrão. Para além disso, esta relação laboral é caracterizada por uma informalidade imposta pela mobilidade que o trabalhador tem face a toda uma estrutura laboral, podendo acumular diversos trabalhos em diversos locais diferentes.

O crescimento visível do número de trabalhadores(as) domésticos(as) ao serviço, a resistência que aparentemente se assiste face à celebração de um contracto laboral, embora exigido por lei, são condições que merecem especial atenção neste estudo.

\section{BIBLIOGRAFIA}

ANDERSON, Bridgest, (2001a), "Different roots in common ground: Transnationalism and migrant domestic workers in London” in Journal of Ethnic \& Migration Studies, Vol. 27 , nº4, p673-683, UBSCO.

ANDERSON, Bridget, (2001b), “Just another Job? Paying for domestic work”, in Gender \& Development, vol. 9, nº 1, pp. 25-33, UBSCO.

ALMEIDA, Ana Nunes (1993), “Mulheres e Família operárias: a «esposa doméstica»”, Análise social, vol.XXVIII (120), (1º), pp. 105-132.

BECK, Elizabeth, (2001),“The National Domestic Workers Union and the war on Poverty”, in Journal of Sociology and Social Welfare, volume XXVII, $\mathrm{n}^{\circ}$ 4, UBSCO.

CHAN, Annie Hau-nung, (2006) “The Effects of Full-Time Domestic Workers on Married Women’s Economic Activity Status in Hong Kong, 1981-2001”, in International Sociology, Vol 21(1): 133-159.

CHABAUD-RYCHTER, Danielle, Dominique Fougeyrollas-Schwebel e Françoise Sonthonnax, (1985), Espace et Temps du Travail Domestique, Méridiens, Paris.

CLARKE, Mary P., (2002), "Domestic work, joy or pain? Problems and solution of the workers”, in Social and Economic Studies, 51: 4. 
COHEN, Rina, (1991) "Women of Color in White Households: Coping Strategies of Live-in Domestic Workers.” Qualitative Sociology, Vol. 14 Issue 2, p197, UBSCO.

COLE, Jeffrey, (2006), "Domestic work life and immigration in Sicily”, Journal of Modern Italian Studies, 11:1, 22-36, UBSCO.

COLE, Jeffrey and Sally Booth. 2006. "Domestic Work, Family Life, and Immigration in Sicily." Journal of Modern Italian Studies 11(1): 22-36, UBSCO.

COX, Rosie, Watt, Paul, (2002) "Globalization, polarization and the informal sector: the case of paid domestic workers in London”, in Area, Vol. 34 Issue 1, p39, UBSCO.

DILL, B., (1994), Across the boundaries of race and class: an exploration of work and family among black domestic servants, New York: Garland Press, UBSCO.

DONATH, Susan, “The order of economy: a suggestion for a distinctively feminist economics”, in Feminist Economics, March 2000, 6:1, pp. 115-123.

DUSSUET, A. (1997), Logiques domestiques, essai sur les représentations du travail domestique chez les femmes actives de milieu populaire, Paris, L’Harmattan.

DUSSUET, A. (1999), “Les Logiques Domestiques contre les femmes”, in Les Parcours de vies des femmes - Travail, Famille et Représentations Publiques, Paris, L’Harmattan.

ENGELS, F. (1970), A Origem da Família da Propriedade Privada e do Estado, Lisboa: Presença.

GUERREIRO, Maria das Dores, Pereira, Inês (2006), Responsabilidade social das empresas, igualdade e conciliação trabalho-família : experiências do prémio igualdade é qualidade, Lisboa : Comissão para a Igualdade no Trabalho e na Emprego.

GUERREIRO, Maria das Dores, Pedro Abrantes. (2004), Transições incertas: os jovens perante o trabalho e a família, Lisboa : Direcção Geral de Estudos, Estatística e Planeamento.

KERGOAT, Danièle, "La division du travail entre les sexes” in Kergoat, Jacques, (1998), Le Monde du Travail, Paris, la découverte . 
KOUSHA, M. (1995), “African American private household workers, white employees and children.” in International journal of Sociology, 25, 67-89.

ROLLINS, J. (1985), Between women: domestics and their employers, Philadelphia: Template University Press, UBSCO.

TORRES, Anália, (2004), Vida Conjugal e Trabalho: Uma Perspectiva Sociológica, Oeiras, Celta Editora.

TORRES, Anália (coord.), (2004), Homens e Mulheres entre Família e Trabalho, Lisboa: Comissão para a Igualdade no Trabalho e no Emprego. 
